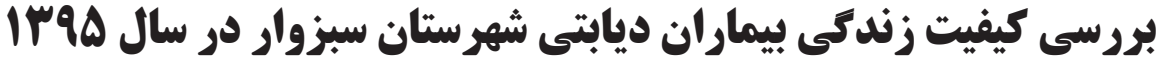

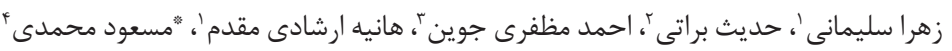

جكيده

مقدمه: كيفيت زندگى بر آيند مهم سلامتى به شمار مىرود و به عنوان يك موضوع اصلى در مراقبت از بيماران مختلف از

جمله بيماران مبتلا به ديابت مورد توجه قرار مى گيرد.

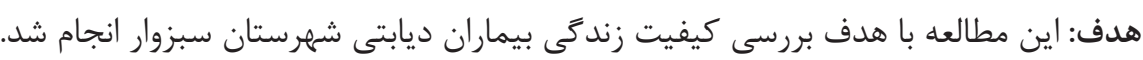

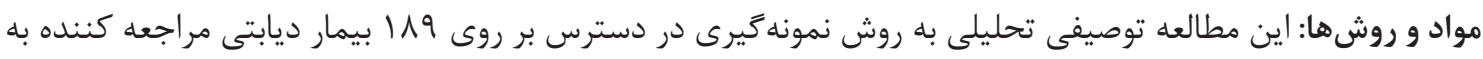

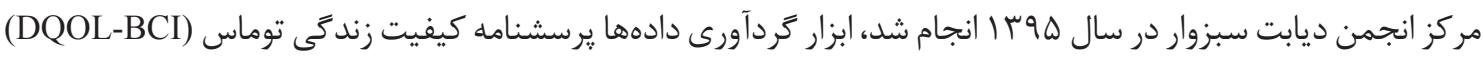

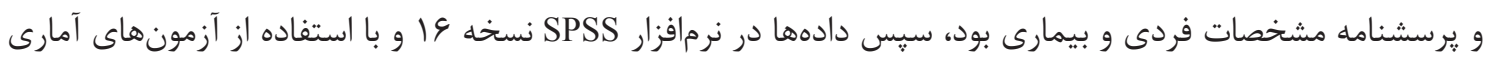

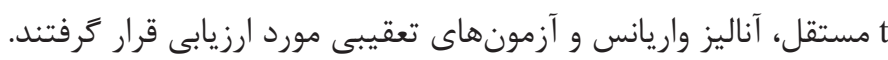

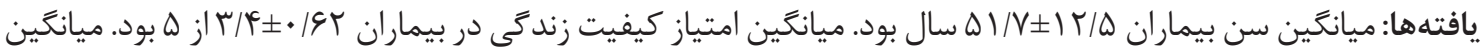

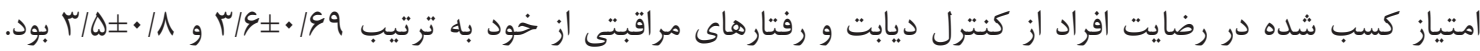

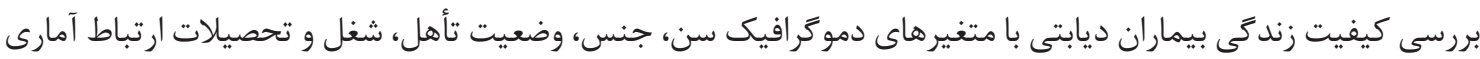

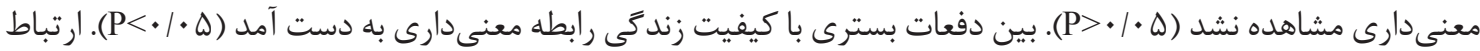
دو حيطه رضايت افراد و رفتارهاى مراقبتى بيماران با سطح تحصيلات ارتباط آمارى معنىدارى را نشان داد (ه •/P<). بحث و نتيجه كيرى: با توجه به ارتباط كنترل ديابت و رفتارهاى خود مراقبتى بر مطلوب بودن كيفيت زندگى ييشنهاد


كلمات كليدى: ديابت، رفتارهاى خود مراقبتى، كيفيت زندگى.

\begin{tabular}{|c|c|c|}
\hline १८/१/ґ० & 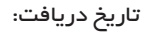 & 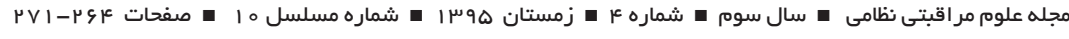 \\
\hline $9 \Delta / 1 \circ / 11$ & ت تاريخ يذيرش: & \\
\hline $9 \Delta / 1 \mu / 10$ & 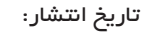 & \\
\hline
\end{tabular}

در كشورهاى آسيايى r تا ه برابر بيشتر از بيمارىهاى عفونى

مقلمهه

امروزه روند بيمارىها و مرى و مير در بسيارى از كشورهاى است (1).

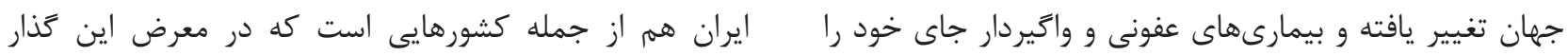

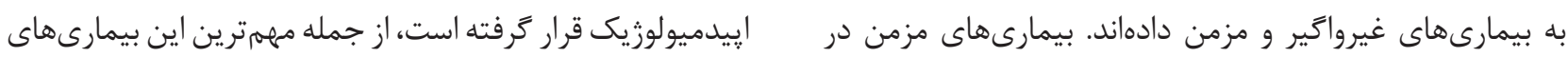

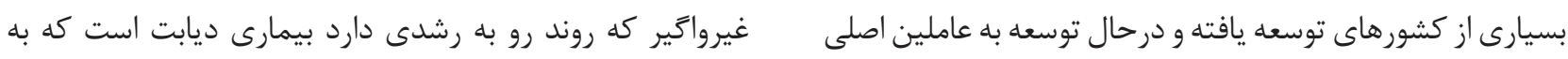

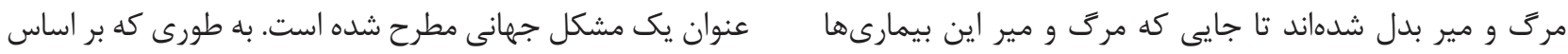

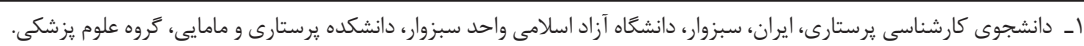

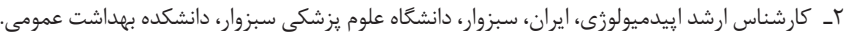

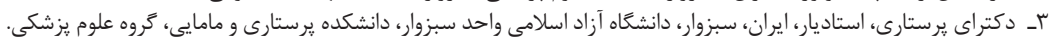

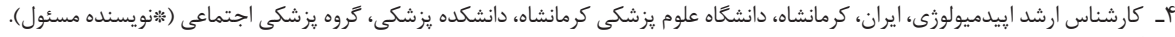
آدرس الكترونيك: masoud.mohammadi1989@yahoo.com 
زندَى بيماران ديابتى را زمينه اصلى كاهش هزينههاى تحميلى

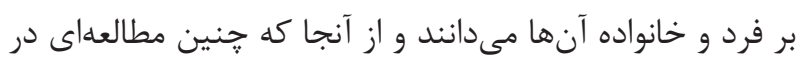
شهرستان سبزوار انجام نشده و مطالعات ديكر (ها -9 (1) لزوم

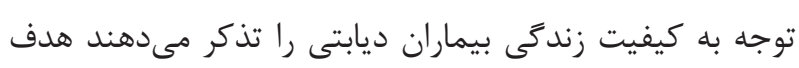

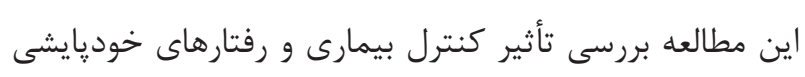

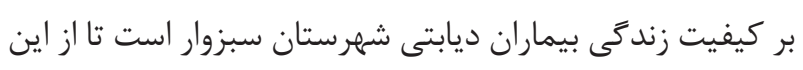

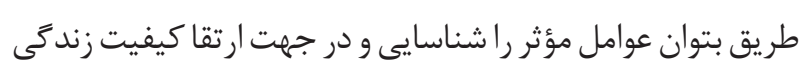
اين بيماران و اقدامات خود مراقبتى بيشتر كوشيد.

\section{مواد و روشها}

اين مطالعه توصيفى تحليلى بوده كه تعداد نمونه با استفاده از $n=\frac{Z_{1-\frac{\alpha}{r}}^{r} \delta^{r}}{d^{r}}$

(ه) صورت نمونه گيرى در دسترس از بيماران ديابتى مراجعه كننده

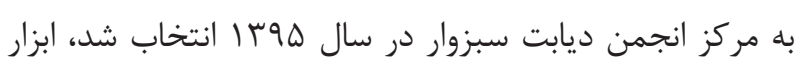

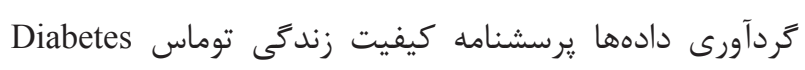
Quality of Life - Brief Clinical Inventory (DQOL-BCI) كه شامل •و سؤال مىباشد و در سال 9191 توسط جاكبسون

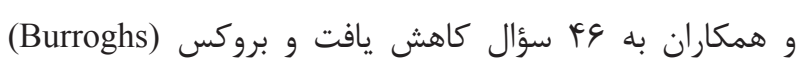



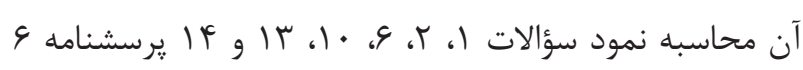
سؤالى هستند كه ميزان رضايت از كنترل ديابت در فرد بيمار

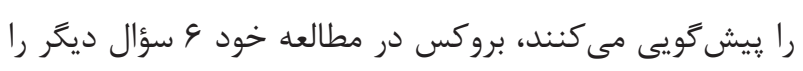

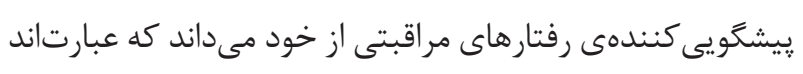

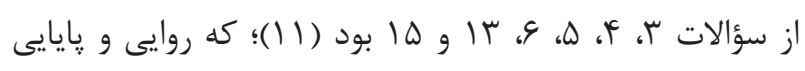

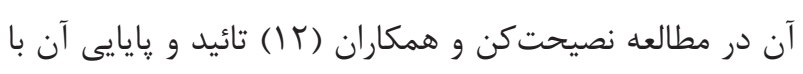



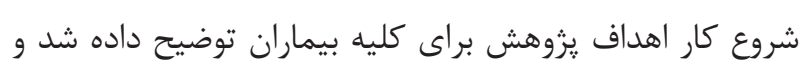
از آنها جهت شركت در مطالعه رضايتنامه كتبى اخذ شد (اين بردي يرسشنامهها به منظور حفظ ملاحظات اخلاقى و محرمانه ماندن اطلاعات بيماران با رضايت كامل بيمار و بدون ذكر نام موردات مورد

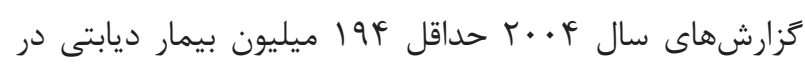
سراسر جهان بوده و بنا بر بيشبينى سازمان جهانى بهداشت تعداد

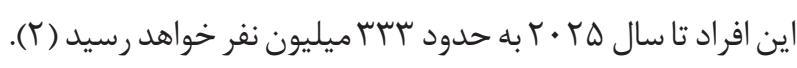

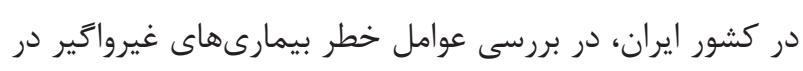

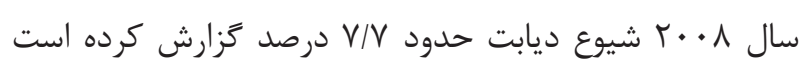

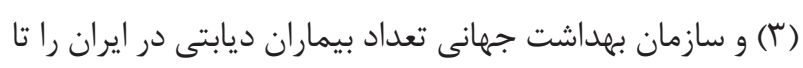

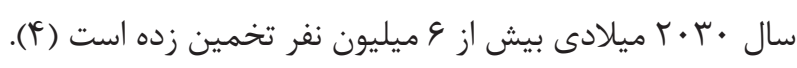

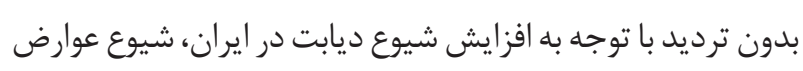

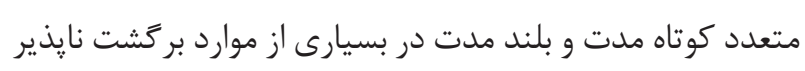

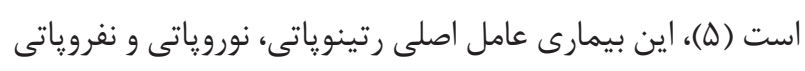



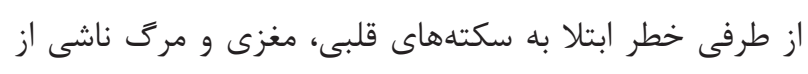

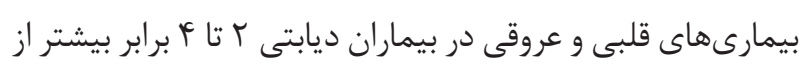

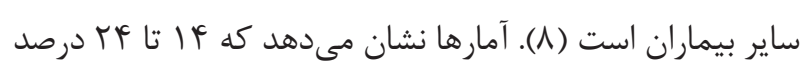

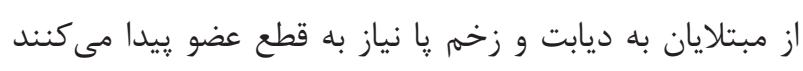

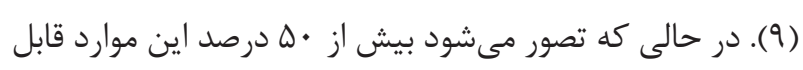

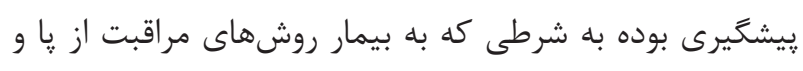
خودمراقبتى آموزش داده شود (• (1).

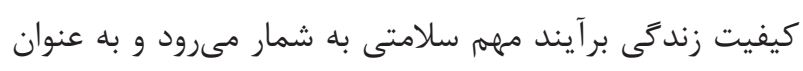

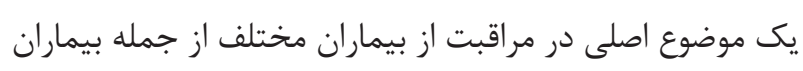

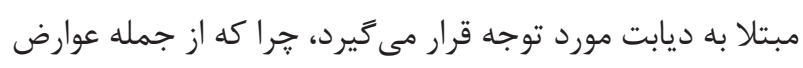

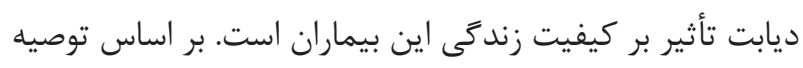

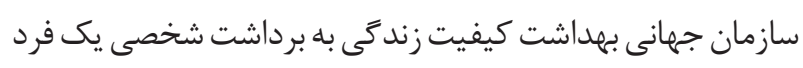

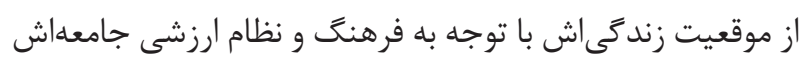

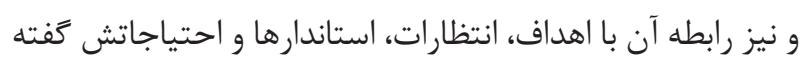

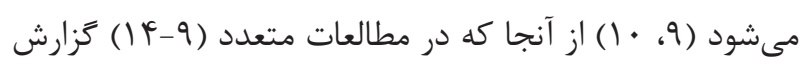
شده است كه ديابت بيمارى مزمنى بوده كه كيفيت زند مَى بيماران

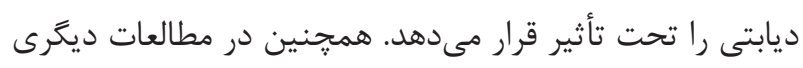
كه در كشور انجام شده است شيوع ديابت خصوصاً ديابت نوع دئي

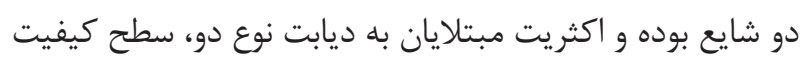

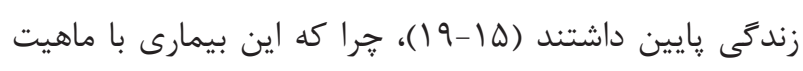



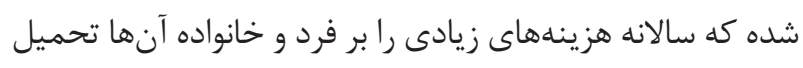

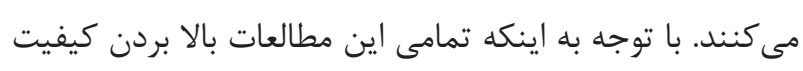


جدول ا - مشخصات دموكر افيك نمونهى مورد يزوهش

\begin{tabular}{|c|c|c|c|}
\hline درصد & تعداد & \multicolumn{2}{|c|}{ مشخصات دموكر افيك } \\
\hline $19 / 9$ & $r v$ & كمتر از • F سال & \multirow{3}{*}{ سن } \\
\hline$f q / r$ & 94 & أf تا • ع سال & \\
\hline$r \cdot / V$ & $\Delta \Lambda$ & • ع سال و بالاتر & \\
\hline rq/ & $V \Delta$ & مرد & \multirow{2}{*}{ جنس } \\
\hline $9 \cdot / \pi$ & $11 \mathrm{~F}$ & زن - ت ان & \\
\hline GN/r & 149 & زير دييلم & \multirow{4}{*}{ تحصيلات } \\
\hline$I T / V$ & TF & دييلم & \\
\hline$r / \Lambda$ & 9 & فوق دييلم & \\
\hline $1 \pi / \Lambda$ & re & ليسانس و بالاتر & \\
\hline$\Lambda \varepsilon / T$ & 194 & متأهل & \multirow{4}{*}{ وضعيت تأهل } \\
\hline $1 / 1$ & $r$ & مطلقه & \\
\hline 9 & IV & بيوه & \\
\hline$r / r$ & 4 & 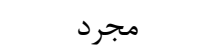 & \\
\hline$r \cdot / V$ & $\Delta \Lambda$ & 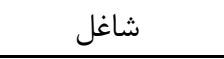 & \multirow{3}{*}{ وضعيت اشتغال } \\
\hline FA/V & 94 & خانهدار & \\
\hline$r \cdot / 1$ & ru & بيكار يا بازنشسته & \\
\hline
\end{tabular}

به ترتيب ميان كيفيت زندگى بيماران ديابتى با متغيرهاى دموگر افيك سن، جنس، وضعيت تأهل، شغل و تحصيلات ارتباط آمارى معنى دارى مشاهده نشد (ه> P> (P). نتايج بررسى ارتباط دو حيطه رضايت افراد و رفتارهاى مراقبتى بيماران با سطح تحصيلات ارتباط آمارى



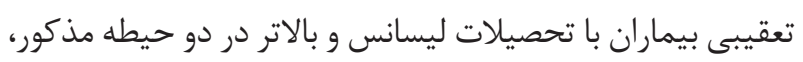

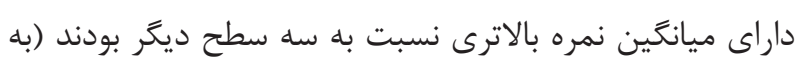

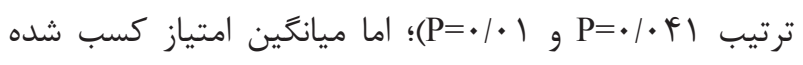
بيماران با تحصيلات فوق دييلم، دييلمم و پايينتر از دييلم اختلاف

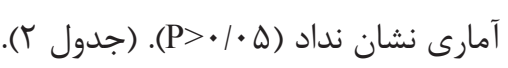

از يزوهشخران سؤالات براى فرد بيمار خوانده شد و ياسخهاى آنان توسط يزوهشكر ثبت شد، اين ڤرسشنامه از دو بخش تشكيل شده است، بخش اول شامل اطلاعات دموكرافيك بيماران و بخش دوم

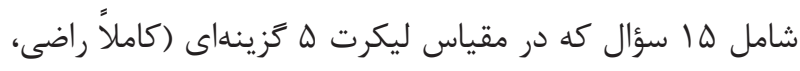
راضى، متوسط، ناراضى، كاملاً نار اضى) تنظيم شده بود، هر بيمار

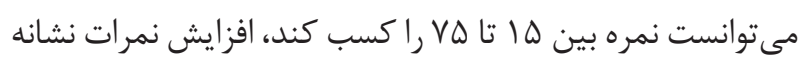
بهبود كيفيت زندگى است، سطح كيفيت زندگى به سه سطح تقسيم شد، به طورى كه افراد كه VD٪ نمره را كسب مى كردند داراى كيفيت زندگى مطلوب، بين • ه تا Vه٪ نمره داراى كيفيت زندگى نسبتاً مطلوب (متوسط) و كمتر از • ه.٪ نمره داراى كيفيت

زندگى نامطلوب (يايين) بودند (1) (1). اطلاعات نمونههاى مورد بررسى با كسب موافقت آكاهانه و

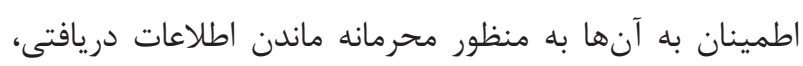
كسب شد. يس از تكميل دادههاى جمع آورى شده وارد نرمافزار

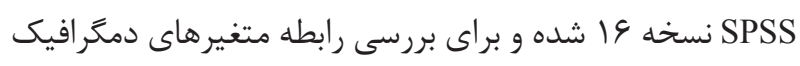
از آزمونهاى آمارى t مستقل (جنس) و آناليز واريانس (سن، وضعيت تأهل، تحصيلات و اشتغال) و آزمونهاى تعقيبى شفه مورد استفاده قرار كرفتند.

\section{يافتهها}

در اين مطالعه 119 فرد مبتلا به ديابت مورد بررسى قرار

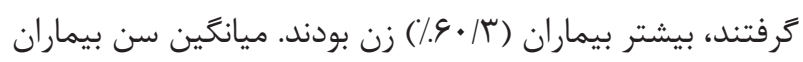
| از نظر نوع ديابت تعداد افراد مبتلا به ديابت نوع دو، نوع يك و

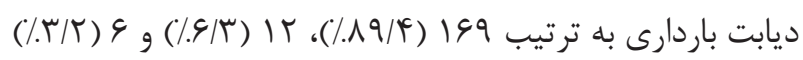

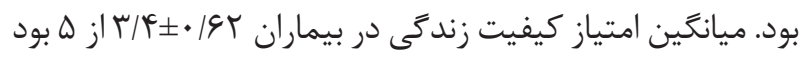

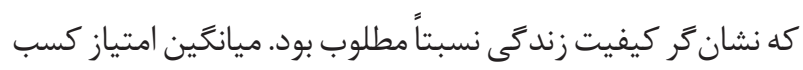
شده در رضايت افراد از كنترل ديابت و رفتارهاى خود مراقبتى

جدول r- تعيين ار تباط بين سطح تحصيلات با كيفيت زندگى بيماران، رضايت بيماران و رفتارهاى مراقبتى از خود در جامعه مورد يثوهش

\begin{tabular}{|c|c|c|c|c|c|}
\hline Pyalue - & ليسانس و بالاتر & فوق دييلم & دييلم & زير دييلم & حيطه \\
\hline Paiue & انحراف معيار士 ميانغين & انحراف معيار土 ميانگين & انحراف معيار土 ميانگين & انحر اف معيار土 ميانگين & \multirow{2}{*}{ رضايت افراد از كنترل ديابت } \\
\hline $.1 \cdot 48$ & $r / \Lambda \Lambda \pm \cdot \mid q r$ & $r / F F \pm \cdot / V V$ & $r / G \Lambda \pm \cdot / V r$ & $r / 4 \wedge \pm \cdot / 99$ & \\
\hline$\cdot 1 \cdot r$ & $r / q F \pm \cdot|\Delta|$ & $\Gamma / \Delta \pm \cdot / \Lambda \varphi$ & $r / 9 \pm \cdot / 9 \Delta$ & $r / \Delta \pm \cdot$ & رفتارهاى خود مراقبتى \\
\hline$\cdot 1 \cdot 9$ & $r / V G \pm \cdot / \Delta V$ & $r / 4 q \pm \cdot 19 \Delta$ & $r / \Delta Y \pm \cdot / V r$ & $r / F T \pm \cdot / Q$ & كيفيت زندكى كلى بيماران \\
\hline
\end{tabular}


جدول بـ - تعيين ارتباط بين سابقه بسترى با كيفيت زندكى بيماران، رضايت بيماران و رفتار هاى مراقبتى از خود در جامعه مورد يثوهش

\begin{tabular}{|c|c|c|c|c|}
\hline \multirow{2}{*}{ Pvalue } & سابقه بسترى دو بار و بيشتر & سابقه بسترى يك بار & بدون سابقه بسترى & \multirow{2}{*}{ حيطه } \\
\hline & انحراف معيار土 ميانغين & انحراف معيار士 ميانگين & انحراف معيار土 ميانگين & \\
\hline $\mathrm{P}<\cdot / \cdot \cdot 1$ & $\Gamma / \| \pm \cdot / V$ & $r / r \& \pm \cdot \mid 9 r$ & $r / 9 \Lambda \pm \cdot 199$ & رضايت افراد از كنترل ديابت \\
\hline $\mathrm{P}<\cdot 1 \cdot \cdots 1$ & $T / T F \pm \cdot / V$ & $r / r q \pm \cdot / \Delta V$ & $r / 99 \pm \cdot 191$ & رفتارهاى مراقبتى از خود \\
\hline $\mathrm{P}<\cdot / \cdot \cdot 1$ & $r / 1 r \pm \cdot|9|$ & $r / T| \pm \cdot| \Delta r$ & $r / \Delta 9 \pm \cdot / 9$ & كيفيت زندكى كلى بيماران \\
\hline
\end{tabular}

مطالعه ديخرى از : يرهام و همكاران گزارش شد كه ميانخين سنى

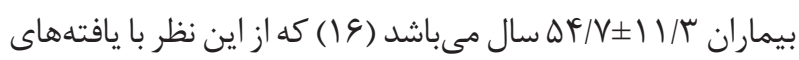
اين مطالعه مشابهتهايى دارد. در اين مطالعه از نظر نوع ديابت تعداد افراد مبتلا به ديابت نوع دو،

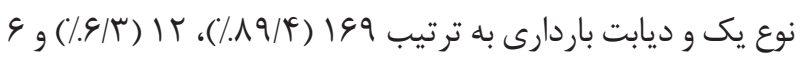

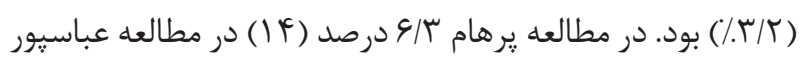

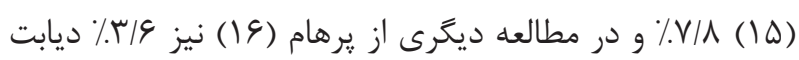

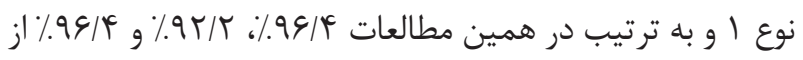
بيماران دجار ديابت نوع دو بودند كه مانند مطالعه حاضر بيشترين فراوانى را مبتلايان ديابت نوع دو تشكيل مىدادند.

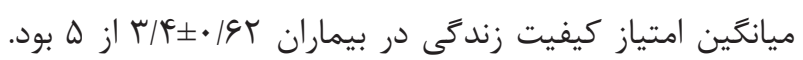
ميانگين امتياز كسب شده در رضايت افراد از كنترل ديابت و رفتارهاى مراقبتى از خود به ترتيب \&9/ • • بررسى ارتباط ميان كيفيت زندگى بيماران ديابتى با متغيرهاى دموَر افيك سن، جنس، وضعيت تأهل، شغل و تحصيلات ارتباط

$$
\text { آمارى معنى دارى مشاهده نشد (ه • • (P). }
$$

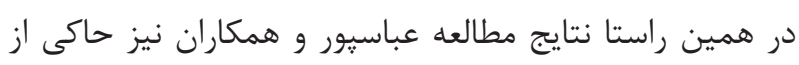
اين بود كه در ا9 درصد بيماران مورد مطالعه ميانگين امتياز

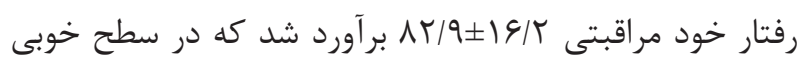
قرار داشت (ه ()، در اين مطالعه ارتباط معنادارى بين رفتار خود مراقبتى و در گيرى اعصاب يا در بيماران مورد مطالعه وجود داشت اما هيجز رابطه معنادارى بين رفتار خود مراقبتى و سن، جنس، مصرف سيعار، شغل، جاقى و زخم پاى ديابتى مشاهده نشد. در مطالعه يرهام و همكاران گزارش شد كه از بين افراد مورد بررسى

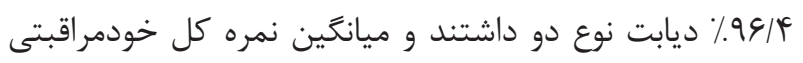

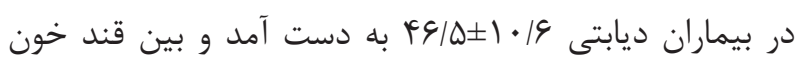
ناشتا و مراقبت از خود، فعاليت فيزيكى و قند خون ناشتا، سطح تحصيلات و خودمراقبتى ارتباط معنادارى وجود داشت (If).
در اين مطالعه بين نوع ديابت و كيفيت زندگى بيماران رابطه معنى دار آمارى مشاهده نشد (ه •|P>). بيماران از نظر تعداد دفعات بسترى به سه گروه بدون سابقه بسترى (VT/)، سابقه يك بار بسترى (19/9/\%) و سابقه بسترى دو بار و بيشتر (1/ • (1/) تقسيم شدند. رابطه بين مدت بسترى و كيفيت زندگى از نظر

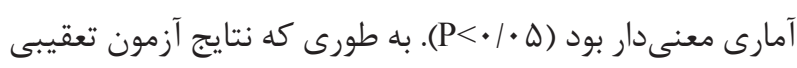
نشان داد بيمار ان بدون سابقه بسترى، ميانيگن نمره كيفيت زندىى بالاترى نسبت به بيماران با يك بار سابقه بسترى (ع + •|•) و

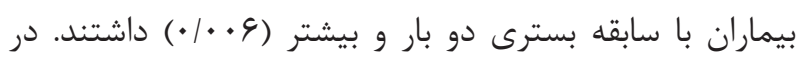
صورتى كه ميانگين نمره كسب شده بيماران با سابقه بسترى يك بار، دو بار و بيشتر تفاوت معنىدارى از يكديخر نداشتند

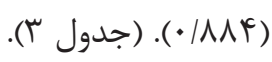
حدود /ه/ه درصد بيماران بيمارى خود را از طريق رزيم غذايى،

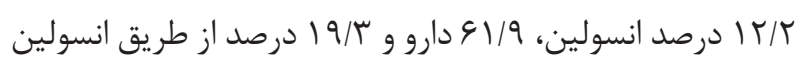
به علاوه دارو كنترل مى كردند. بين روش كنترل ديابت و كيفيت زندگى بيماران، ارتباط معنى دار آمارى مشاهده نشد (ه • • (P). ولى ميانگين كيفيت زندگى بيمارانى كه بيمارى خود را از طريق رزيم غذايى (101/ •

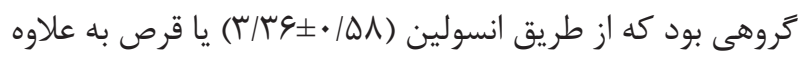

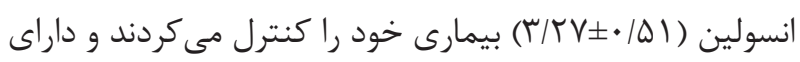
كيفيت زندگى نسبتاً مطلوبى بودند.

\section{بحث و نتيجه كيرى}

هدف اين مطالعه بررسى كيفيت زندكى مبتلايان به ديابت در شهرستان سبزوار بود، در اين مطالعه ميانخين سن بيماران

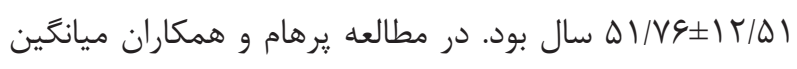
سنى مبتلايان /T/|

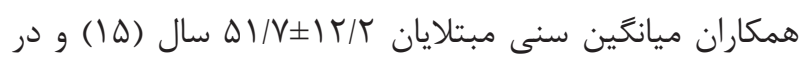




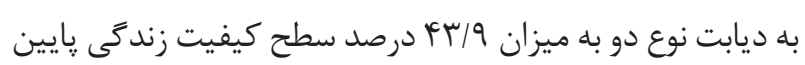

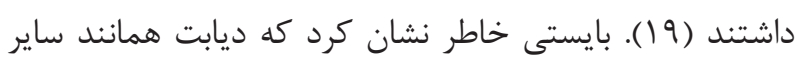

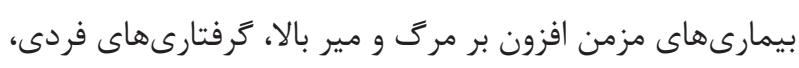

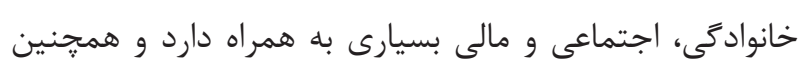

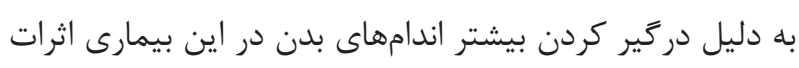

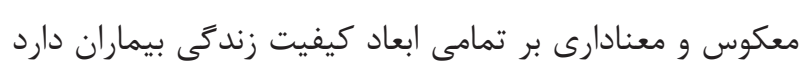

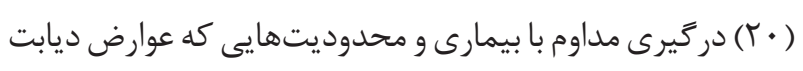

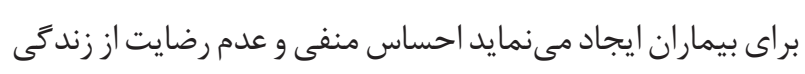

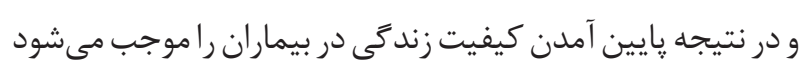

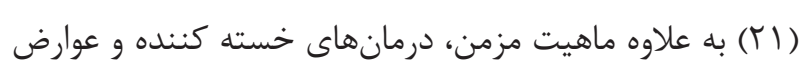
ناتوان ساز و تهديد كننده ديابت ابعاد جسمى، روانى- روحى، دران، اجتماعى و به عبارتى كيفيت زندگى فرد مبتلا را تحت تأثير قرار

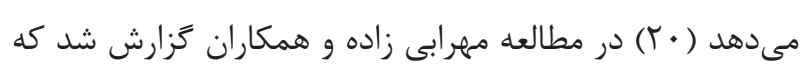

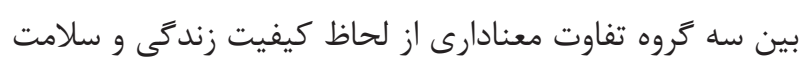

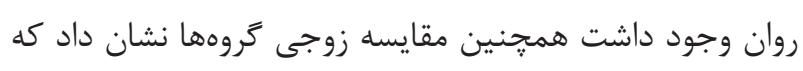

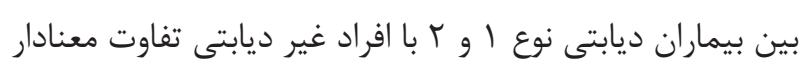
در تغييرهاى كيفيت زندگى و سلامت روان وجود دارد (T) (Y).

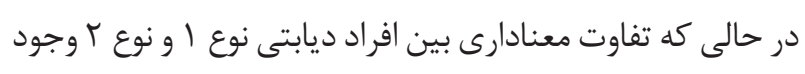
ندارد كه اين مفهوم را بدين تونه مى توان تبيين كرد كه كيفيت

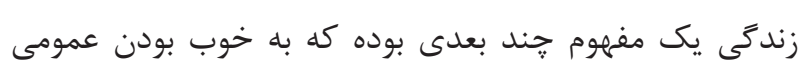

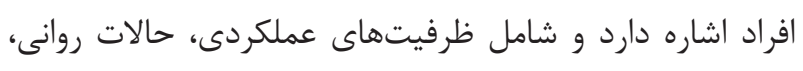

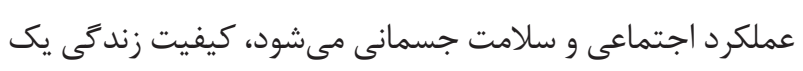
شخص، يك درك شخصى است كه به وسيله احساس افراد درباره

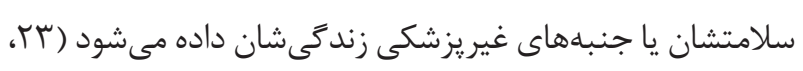
دF به اين ترتيب مى (YF

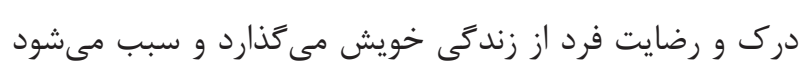
كه ظرفيت عملكردى، حالات روانى و عملكرد اجتماعى و به طور كلى كيفيت زندگى فرد كاهش يابد. در مطالعه آرين و همكاران

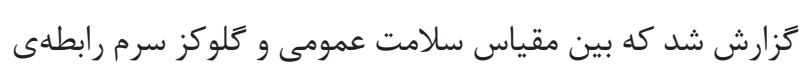
معكوس معنادارى مشاهده شد به طورى كه شانس افزايش قند

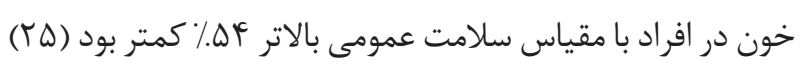

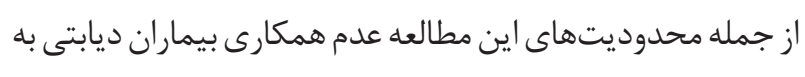

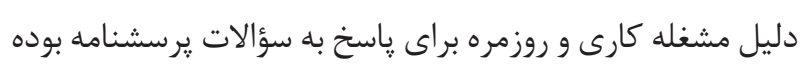
كه با صرف وقت بيشتر نويسندًان براى اين بيماران خوشبختانه

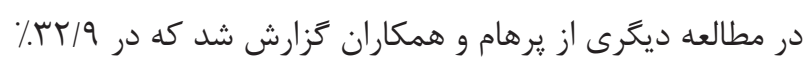

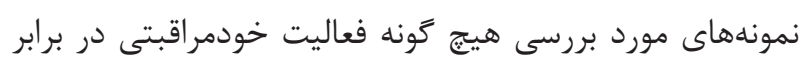

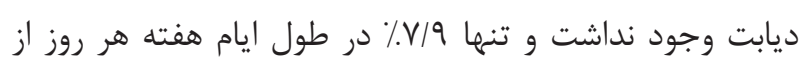
تمام فعاليتهاى خودمراقبتى تبعيت مى كردند، ميانكين نمره

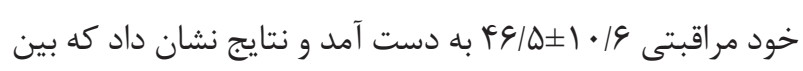
خود مراقبتى و ميزان قند خون ناشتا و نيز همو كلوبين كليكوليزه

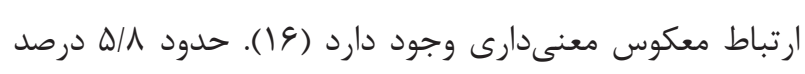



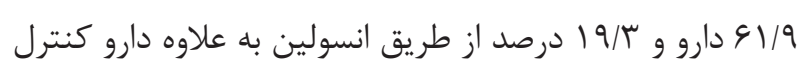

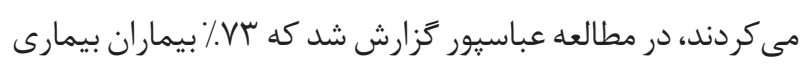

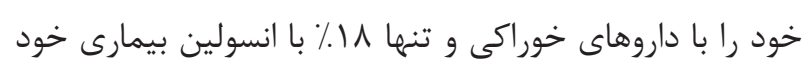

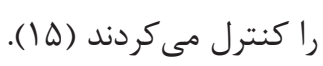
رابطه بين مدت بسترى و كيفيت زندكى از نظر آمارى معنى دار

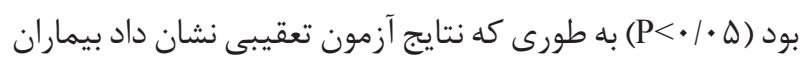

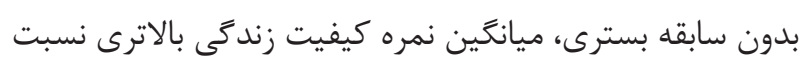

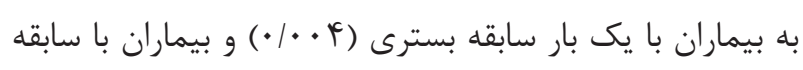

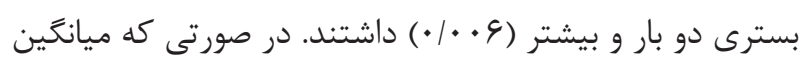
نمره كسب شده بيماران با سابقه بسترى يك بار، دو بار و بيشتر

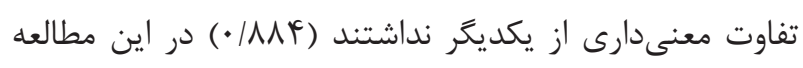

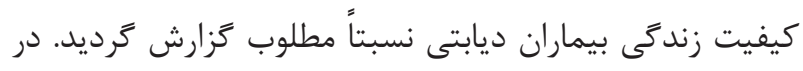

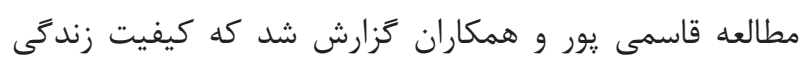

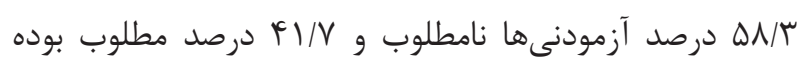

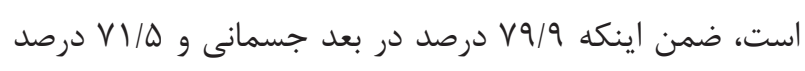
در بعد روانى داراى كيفيت زندگَى نامطلوب بودند، تغييرهاى

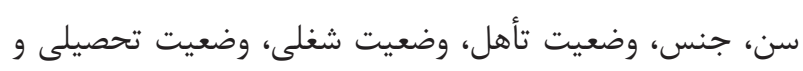

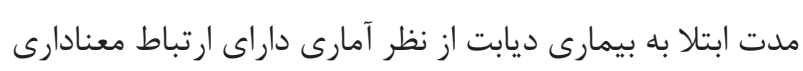

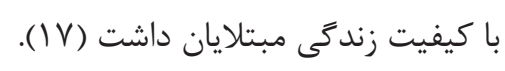
در مطالعه صفوى و همكاران نيز كزارش شد كه بيشتر بيماران


از آزمون كاى دو و ضريب همبستخى نشان داد كه بين ديد داه

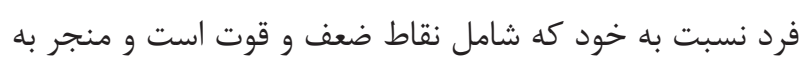

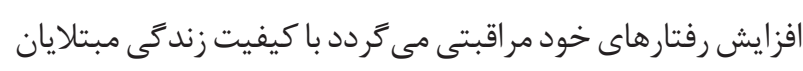
به ديابت نوع دو ارتباط آمارى وجود دارد (1) (1). صمدى و همكار ان در مطالعهاى كزارش كر درند كه اكثريت مبتلايان 
مطالعات مشابه در شهرهاى ديخر كشور نيز انجام شده تا زمينه مقايسه كشورى و دستيابى به اطلاعات معتبرتر و جامعتر براى بهبود كيفيت زندگى بيماران ديابتى در سطح كشور فراهم آيد.

\section{تشكر و قدردانى}

نويسندًان مقاله از همكارى مسئولان مركز انجمن ديابت سبزوار

كه در كمك به جمع آورى دادهها نقش بسزايى داشتند صميمانه

$$
\text { تشكر مىنمايند. }
$$

\section{References}

1- Vongpatanasin W. Cardiovascular morbidity and mortality in high-risk populations: epidemiology and opportunities for risk reduction. J Clin Hypertens (Greenwich). 2007;9(11 Suppl 4):115. PMID: 17978602

2- Li X, Song F, Jiang H, Zhang M, Lin J, Bao W, et al. A genetic variation in the fat mass- and obesity-associated gene is associated with obesity and newly diagnosed type 2 diabetes in a Chinese population. Diabetes Metab Res Rev. 2010;26(2):128-32. DOI: 10.1002/dmrr.1066 PMID: 20186840

3- Esteghamati A, Gouya MM, Abbasi M, Delavari A, Alikhani S, Alaedini F, et al. Prevalence of diabetes and impaired fasting glucose in the adult population of Iran: National Survey of Risk Factors for Non-Communicable Diseases of Iran. Diabetes Care. 2008;31(1):96-8. DOI: 10.2337/dc07-0959 PMID: 17921357

4- World Health Organization. Prevalence of Diabetes in the Who Eastern Mediterranean Region: Diabetes Programmer 2012 [updated 2015; cited 2012]. Available from: http://www.who.int/ diabetes/facts/world_figures/en/index $2 . h t m l$.

5- Funnell MM, Brown TL, Childs BP, Haas LB, Hosey GM, Jensen B, et al. National Standards for diabetes self-management education. Diabetes Care. 2011;34 Suppl 1:S89-96. DOI: 10.2337/ dc11-S089 PMID: 21193633

6- Bell RA, Arcury TA, Snively BM, Smith SL, Stafford JM, Dohanish R, et al. Diabetes foot self-care practices in a rural triethnic population. Diabetes Educ. 2005;31(1):75-83. DOI: 10.1177/0145721704272859 PMID: 15779248

7- Majra J, Acharya D. Awareness regarding self care among diabetics in rural India. Middle East J Fam Med. 2009;7(6):11-4.

8- Mody R, Kalsekar I, Kavookjian J, Iyer S, Rajagopalan R, Pawar V. Economic impact of cardiovascular co-morbidity in patients with type 2 diabetes. J Diabetes Complications. 2007;21(2):75-83. DOI: 10.1016/j.jdiacomp.2006.02.005 PMID: 17331855

9- Honarmand M, Eidi Baigi M, Davoodi IC. [Comparison quality of life and mental health in diabetics with type 1 and 2 and nondiabetics in Yazd]. Yazd J Uni Med Sci. 2012;10(7):654-62.

$$
\text { تمامى اطلاعات بيماران جمعآورى گرديد. }
$$

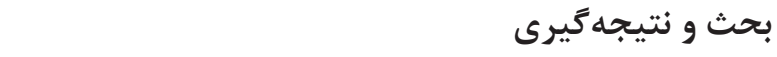

با توجه به اثر كنترل ديابت و رفتارهاى خودمراقبتى بر مطلوب بودن كيفيت زندگى بيشنهاد مىشود بر رفتارهاى خودمراقبتى به جهت ارتقا كيفيت زندگى بيماران ديابتى توجه بيشترى صورت كيرد تا بتوان از عوارض شديد بيمارى ديابت در بيماران و تحميل هزينههاى درمانى بالا به خانواده آنها كاست. ييشنهاد مىشود

Jahaddaneshghahi press; 2010.

11- Burroughs TE, Desikan R, Waterman BM, Gilin D, McGill J. Development and Validation of the Diabetes Quality of Life Brief Clinical Inventory. Diabet Spectrum. 2004;17(1):41-9. DOI: 10.2337/diaspect.17.1.41

12- Nsyhtkn A, Pishua A, Hbybzadh F, Tabatabai M, Qshqayyzadh T, Hafizi F. [Determine the reliability and validity of clinical summary quality of life of diabetic patients (DQOL) to Persian]. J Diabet Lipid Disord. 2012;11(5):483-7.

13- Monjamed Z, Mehran A, Peimani T. [The quality of life in diabetic patients with chronic complications]. J Hayat. 2006;12(1):55-66.

14- Parham M, Riahin A, Jandaghi M, Darivandpour A. [Self care behaviors of diabetic patients in Qom]. Qom Uni Med Sci J. 2013;4(6):81-7.

15- Abbaspour S, Shamaeiyan N, Hasanzadeh M, Zandi Z, Sepehri A. [Self-care behaviors among diabetic patients referred to a selected hospital clinic in Torbat-e-Heydarieh]. J Torbat Heydariyeh Uni Med Sci. 2013;1(1):65-70.

16- Parham M, Rasooli A, Safaeipour R, Mohebi S. [Assessment of effects of self-caring on diabetic patients in Qom diabetes association 2013]. Quart J Sabzevar Uni Med Sci. 2014;21(3):47384.

17- Haririan H, Moghadasian S, Aghajanlou A. [Quality of life and its dimensions in diabetic patients referred to diabetes center of Tabriz medical university]. Iran J Diabet Lipid Disord. 2009;9(2):152-60.

18- Safavi M, Samadi N, Mahmoudi M. [Study concept and its relationship to quality of life in patients with type 2 diabetes]. Med J. 2013;23(2):148-53.

19- Samadi N, Safavi M, Mahmoodi M. [The relationship between quality of life and self-esteem in patients with Type 2 diabetes in Ardabil 2011: A short report]. J Rafsanjan Uni Med Sci. 2013;12(3):251-6.

20- Baghery H, Ebrahimi H, Taghavi N, Hasani M. [Evaluation of quality of life in patients with diabetes mellitus, based on its complications, referred to Emam Hossein Hospital, Shahroud]. J Shahrekord Univ Med Sci. 2005;7(2):50-6. 
21- Gutteling JJ, Duivenvoorden HJ, Busschbach JJ, de Man RA, Darlington AS. Psychological determinants of healthrelated quality of life in patients with chronic liver disease. Psychosomatics. 2010;51(2):157-65. DOI: 10.1176/appi. psy.51.2.157 PMID: 20332291

22- Ghofranipour F, Sobhani A, Kimmiagar M, Vafaei M. [Evaluating curvilinear hypothesis in quality of life and glycemic control in diabetic patients]. Arak Med Uni J. 2008;11(2):27-34.

23- Mehrabizadeh Honarmand M, Eydi Baygi M, Davodi I.
[Comparing the quality of life and mental health of patients with diabetes type I, II and non-diabetic individuals in Ahwaz]. Iran J Res Behav Sci. 2013;10(7):654-62.

24- Abasi A. [Effect of exercise program on functional ability and quality of family life in patients with heart failure]. Ahvaz, Iran: Jundishapur University; 2006.

25- Arian V, Farvid M, Montazeri A, Yavari P. [Association between health-related quality of life and glycemic control in type 2 diabetics]. Iran J Endocrin Metab. 2012;14(4):318-24. 


\title{
The Quality of Life of Patients with Diabetes from the City of Sabzevar During Year 2016
}

\author{
Solimani. $\mathrm{Z}^{1}$, Barati $\mathrm{H}^{2}$, Mozafari. Join $\mathrm{A}^{3}$, Ershadi Moqadam. $\mathrm{H}^{1}$, *Mohammadi. $\mathrm{M}^{4}$
}

\begin{abstract}
Introduction: Quality of life is an important health marker and a major topic in the care of patients with diabetes.

Objective: The aim of this study was to assess the quality of life of patients with diabetes in the city of Sabzevar.

Materials and Methods: This cross-sectional study was performed on 189 patients with diabetes referred to the Diabetes Association of Sabzevar during year 2016. For data collection the Thomas quality of life questionnaire (DQOLBCI) and a demographic questionnaire were used, and for data analysis the SPSS 16 software was employed using the independent $t$ test, Analysis of Variance (ANOVA) and post hoc test.

Results: The mean age of patients was $51.7 \pm 12.5$ years. Average rating of quality of life in patients was $3.4 \pm 0.62$ out of 5. The mean score of personal satisfaction of diabetes and self-care behaviors was $3.6 \pm 0.69$ and $3.5 \pm 0.8$, respectively. There was no statistically significant relationship between quality of life of patients with diabetes and demographic variables of age, gender, marital status, occupation and education. A significant relationship was found between frequency of hospitalization and quality of life $(\mathrm{P}<0.05)$. The correlation between the two areas of satisfaction and patient care behaviors was statistically significant with education $(\mathrm{P}<0.05)$.
\end{abstract}

Discussion and Conclusion: According to the relationship between controlling of diabetes \& on self-care behaviors with patients quality of life, it is suggested that self- care training to be more considered.

Keywords: Diabetes, Quality of life, Self-care Behaviors.

Solimani Z, Barati H, Mozafari Join A, Ershadi Moqadam H, Mohammadi M. The Quality of Life of Patients with Diabetes from the City of Sabzevar During Year 2016. Military Caring Sciences. 2017; 3 (4). 264-271.

Submission: 10/12/2016 Accepted: 31/12/2016 Published: 5/3/2017

1- BSc in Student of Nursing, Iran, Sabzevar, Islamic Azad University, Medical Sciences Department.

2- MSc in Epidemiology, Iran, Sabzevar, Sabzavar University of Medical Sciences, Faculty of Public Health.

3- PhD in Nursing, Assistant Professor, Iran, Sabzevar, Islamic Azad University, Medical Sciences Department. 